\title{
Ayurveda - a medicina clássica indiana
}

\author{
Ayurveda - the classical indian medicine
}

\author{
Antonio Cesar Ribeiro Silva Deveza
}

Deveza ACRS. Ayurveda - A medicina clássica indiana / Ayurveda - the classical indian medicine. Rev Med (São Paulo). 2013 jul.set.,92(3):156-65.

RESUMO: O objetivo do presente artigo é apresentar de forma sucinta as bases da Medicina Clássica Indiana, o Ayurveda. A palavra sânscrita Ayurveda significa literalmente o conhecimento (veda) da longevidade (ayus). Apresentamos um histórico das principais influências de outras medicinas ancestrais que conviveram com o Ayurveda, principalmente graças às várias invasões que o território indiano sofreu ao longo de toda sua história. Diferenciamos o Ayurveda de caráter experimental e de refinada observação de sintomas e sinais das doenças de outras formas de medicina mística praticadas no mesmo território indiano por sacerdotes brâmanes ritualistas. São delineados os princípios fundamentais do Ayurveda, desde a Filosofia Samkhya que oferece suas bases metafísicas, passando pela doutrina dos três humores (tridosha vidya) e dos cinco elementos básicos, pela fisiopatologia com a descrição das várias etapas evolutivas das doenças e seus prognósticos e pela funcionalidade dos sete tecidos corporais, tanto na sua forma saudável como patológica. Descrevemos também os canais de circulação (srotamsi) com suas respectivas funções de conduzir materiais densos como o sangue, a transpiração, as fezes e a urina, bem como os canais de energia sutil responsáveis pela condução dos pensamentos e das funções mentais. As técnicas de diagnóstico são também apresentadas em conjunto com as variadas formas de tratamento, baseadas em terapias mente-corpo como as práticas de ioga e meditação.

DESCRITORES: Medicina Ayurvédica; Medicina integrativa; Saúde holística; Cuidados médicos; Terapias mente-corpo; Filosofia médica; Medicina tradicional; História da medicina; Ioga; Diagnóstico precoce.

\begin{abstract}
The aim of this article is to introduce briefly the foundations of the Classical Indian Medicine, Ayurveda. The Sanskrit word Ayurveda literally means the knowledge (veda) of longevity (ayus). We present a history on the main influences of other ancient medicines that coexisted with Ayurveda, due to the several invasions that the Indian Territory suffered throughout all of its history. Ayurveda has an experimental character and a refined observation of symptoms and signs of diseases, distinct from other forms of mystic medicines practiced within the Indian Territory by orthodox Brahmins priests. The fundamental principles of Ayurveda go from the Samkhya Philosophy that offers its metaphysical bases, through the three humours (tridosha vidya) and five basic elements doctrines, the pathophysiology with the description of the numerous evolutionary steps of diseases and prognosis according to functionality of the seven basic body tissues, in both their healthy and pathological forms. Likewise, we describe the channels of circulation (srotamsi) with their respective functions of conducting dense materials such as blood, perspiration, feces and urine, as well as the subtle energy channels, responsible for the conduction of thoughts and mental functions. The diagnostic techniques are also presented, along with the various possible forms of treatment, based in mind-body therapies as yoga and meditation practices.
\end{abstract}

KEYWORDS: Medicine Ayurveda; Integrative medicine; Holistic health; Medical care; Mind-body therapies; Philosophy, medical; Medicine, traditional; History of medicine; Yoga; Early diagnosis.

ProSER - Programa de Saúde, Espiritualidade e Religiosidade. Instituto de Psiquiatria da Faculdade de Medicina da Universidade de São Paulo.

Endereço para correspondência: Antonio Cesar Ribeiro Silva Devesa. Rua Alvarenga, 616 - São Paulo, SP. CEP: 05509-000. e-mail: deveza@uol.com.br 


\section{Histórico}

palavra Ayurveda significa literalmente
"Conhecimento ou Ciência (veda) da
longevidade (ayus). Situar historicamente as fontes iniciais do Ayurveda é um trabalho provavelmente impossível. A cultura indiana de língua sânscrita surpreendentemente preservou muitos textos antigos pela tradição de conhecimento oral, de mestre a discípulo (a escrita só passa a ser importante como transmissão de conhecimento no período do rei Açoka, imperador indiano da dinastia Máuria que reinou entre 273 e 232 a.C.). Assim, embora tenhamos um rico e extenso material disponível para pesquisa, temos também lacunas importantes que nos impedem de montar de forma adequada esse quebra cabeça de aproximadamente cinco mil anos de história. Porém é consenso entre os vários autores que algumas práticas médicas estiveram presente durante todo o desenvolvimento da cultura indiana, desde os mais remotos tempos e que essas ideias foram se organizando e tornando o Ayurveda um corpo de doutrina unificado e organizado já por volta do século V a.C., quando alguns textos de tradição acadêmica e familiar começaram a ser produzidos (p.2). ${ }^{1}$ Se historicamente é difícil localizar o Ayurveda em todas as suas raízes, certamente delimitar seu alcance é tarefa mais fácil. Inicialmente sua influência foi marcante em todo o subcontinente indiano, mas acabou se disseminando para regiões vizinhas e distantes. Muito dessa expansão se credita às rotas de comércio em que a Índia tinha um papel central, por ser grande produtora de especiarias, produtos agrícolas e seda. Exatamente pela riqueza de produtos e pelas terras extremamente férteis em virtude de seus caudalosos rios, a Índia sempre atraiu o interesse de povos vizinhos, o que explica as constantes invasões do seu território de povos oriundos de todas as direções, como persas, gregos, até o séc. III a.C., mongóis no início da nossa era, hunos eftalitas, por volta do século VI e árabes, entre os séculos VII e X da nossa era. Embora se saiba que todo contato entre povos diferentes determine trocas culturais importantes, a relação entre a cultura grega e a indiana parece ter sido a mais rica. Relatos desse contato já eram descritos alguns séculos antes, mas uma das mais importantes campanhas de invasão do território indiano pelos gregos, com influência culturais bilaterais foi a ocupação de Alexandre da Macedônia, no século IV a.C. Alexandre "O Grande" tinha como característica respeitar a cultura e a religião dos povos dominados o que, em território indiano, favoreceu uma ampla miscigenação cultural em várias áreas do saber como na matemática, na astronomia, na filosofia, na construção e sobretudo na medicina. Há relatos que em alguns antigos reinos indianos, transformados em satrapias gregas pela invasão da Índia, soldados gregos picados por serpentes, deveriam ser tratados exclusivamente por médicos do Ayurveda, pela excelência e eficiência dos seus antídotos contra vários venenos, inclusive os de animais peçonhentos. É possível que dois séculos antes de Alexandre, Hipócrates já tivesse estado em território indiano. Um grande ponto em comum entre as medicinas grega e indiana é sua base na teoria dos humores, defendida na Grécia, por Hipócrates e Galeno, na determinação das constituições dos vários indivíduos e suas tendências às mais variadas doenças físicas e mentais. Hipócrates também defendia seus conhecimentos em saúde no caminho de métodos terapêuticos reprodutíveis e baseados em evidências de resultados comprovados, a exemplo do que faziam também, os grandes autores do Ayurveda antigo (p.xvi). ${ }^{2}$

Além das invasões, outro fator que determinou a disseminação do Ayurveda por fatores intrínsecos ao próprio cenário indiano foi a migração de monges budistas, por volta do século $\mathrm{V}$ a.C. para reinos vizinhos e distantes, perseguidos por razões políticas e religiosas em território indiano. Levavam consigo, além do conhecimento religioso, técnicas de tratamento médico do Ayurveda (p.260). ${ }^{1}$ Eram profundos conhecedores dos preceitos médicos, que utilizavam tanto para seu uso pessoal, como também para levar ajuda humanitária aos povos para os quais levavam a mensagem de Buddha. Alguns desses monges, como Nagarjuna (p.iii), ${ }^{3}$ um dos grandes expoentes do budismo Mahayana, acabaram escrevendo suas próprias obras de Ayurveda, levando esse conhecimento sobretudo para as regiões dos atuais Sri Lanka, Burma, Tibet, Nepal, sul da China, Bangladesh, Laos, Tailândia e outras regiões distantes do oriente, como Mongólia, Malásia, Indonésia e menos incisivamente até o Japão (p.23). ${ }^{4}$

\section{As práticas místicas e a ciência médica}

As práticas místicas sempre foram comuns na Índia, cultura famosa pelos seus laços com valores espirituais, como aqueles encontrados nas práticas psicofísicas do Yoga e no Hinduísmo com seus trezentos e cinquenta milhões de divindades. Esses traços são largamente encontrados nos antigos textos litúrgicos dos Vedas (Rig, Sama, Yajur e Atharvaveda), coleções de extensas obras de hinos religiosos que norteiam as práticas do Hinduísmo. A maioria dos historiadores do Ayurveda concorda que essa mística exerceu forte influência no pensamento médico indiano, sobretudo através do Atharvaveda que além de práticas de encantamentos e tratamentos por métodos místicos já descrevia com detalhes plantas e metais de uso medicinal. Todavia, existem diferenças significativas, tanto no conteúdo como no estilo literário, entre o Atharvaveda e os primeiros textos do Ayurveda que se aproximam mais da linguagem médica de tradições como a grega e a persa, em que as influências religiosas eram muito menores ${ }^{5}$. Embora o misticismo com práticas rituais fosse rejeitado pela medicina indiana clássica, a espiritualidade como parte inseparável da compreensão do homem era fortemente defendida. Isso se comprova sobretudo pela 
concepção de homem e pela definição de saúde e de doença encontrada nos diversos textos do Ayurveda. Assim, o Caraka Samhita, um dos mais respeitados e antigos textos clássicos de Ayurveda, define vida (ayus) como "a perfeita conjunção entre o corpo, os órgãos dos sentidos, a mente e a consciência" (p.6). ${ }^{6}$ Assim, o homem só pode ser totalmente compreendido e considerado na plenitude de sua vida se estiverem em harmonia a sua dimensão física (corpo físico), mental (corpo sensorial e mental) e espiritual (corpo do intelecto e da Consciência). A palavra espiritualidade é extremamente perigosa por enfeixar uma larga gama de sentidos semânticos que podem não corresponder exatamente às possibilidades de compreensão pretendida pelos textos do Ayurveda. Espiritualidade aqui deve ser compreendida como uma capacidade inerente ao homem de abstração e afastamento do mundo concreto, percebido pelos cinco sentidos, e a introspecção e busca de novas experiências percebidas nas inúmeras possibilidades de manifestações do psiquismo.

\section{Princípios básicos do Ayurveda. A visão do Samkhya}

O Ayurveda é um sistema médico apoiado numa história de aproximadamente cinco mil anos. Assim sendo, os vários princípios que norteiam as suas práticas passaram por um processo de evolução ao longo do tempo, decorrente do seu próprio desenvolvimento e da influência de outros sistemas de medicina tanto autóctones (siddha e unani medicine) como estrangeiros (medicinas grega, persa, chinesa).

Uma antiga filosofia da Índia, o Samkhya Darçana, descrita num dos mais antigos textos de Ayurveda, o Susruta Samhita (p.113-6), ${ }^{3}$ defende que o universo surgiu quando o Criador, saindo de um estado de profundo silêncio e meditação decidiu manifestar-se em múltiplos indivíduos. $\mathrm{O}$ processo que teria se originado com o rompimento do silêncio da Consciência Absoluta do Criador manifestouse primariamente como Consciência Individual (vyakti, que significa "o que se manifesta"), no emanar do Seu desejo de se manifestar. Da consciência individual ou desejo de criação surgiu a inteligência pura, que reconhece o que deve ser criado, também chamado de Intelecto ou Mahat que em sânscrito literalmente significa o "o grande". Assim que a inteligência pura determinou com precisão o plano da criação, surgem as mais variadas formas de existência em diferentes indivíduos, ou Egos pessoais, ahamkara na língua original, responsáveis pela memória e pelo instinto de sobrevivência de cada ser criado. A criação dessas múltiplas formas de existência tornou necessários também um aparelho de percepção (para que cada indivíduo criado pudesse perceber o restante da existência, além de si próprio) e também de órgãos com capacidade de ação (para que os indivíduos pudessem interagir mutuamente). Para a interação adequada entre o sentir e o agir, se fez necessário um centro de processamento que, recebendo as informações do aparelho de percepção, comandasse as ações adequadas para cada momento. Assim, os cinco sentidos são nossos órgãos de percepção (visão, audição, paladar, olfato e tato) e são chamados de Jñanendriya; os órgãos de ação, Karmendriya, representam a capacidade de atuação no mundo: comunicação, preensão, locomoção, reprodução e excreção; por fim, Manas ou mente pensante, literalmente, "a função de pensar", recebe as informações dos cinco sentidos e decide a ação que melhor nos adapta ao meio a cada instante. O Ayurveda acredita que toda a forma de existência, animada ou inanimada, é composta por uma Consciência Absoluta (a presença do Criador em cada criatura) ou corpo espiritual, pela Consciência Individual (fruto do desejo e que representa o papel de cada um na história da criação), pelo Intelecto (inteligência sem emoções com capacidade de discernimento entre o certo e o errado no cumprimento do papel individual de cada criatura), pelo Ego (memórias de experiências vividas em cada existência e instinto de sobrevivência), pela Mente Pensante (responsável pelas emoções, dúvidas, fantasias e desejos) que além de ser um órgão de interação entre as informações vindas dos órgãos dos sentidos também determina a ação adequada de adaptação às exigências do meio ambiente), pelos órgão dos sentidos (percepção dos cinco sentidos) e finalmente pelo corpo físico (responsável pelas ações). Quando a relação entre todos esses elementos é harmônica e não há conflitos entre eles, desfrutamos um estado de plena saúde. Por outro lado, a desarmonia da relação de qualquer um desses componentes desencadeia as doenças. Com essas definições podemos entender o conceito de saúde encontrado no Caraka Samhita, versos I.54 e 55 (p.7), ${ }^{7}$ corroborado pelos outros textos clássicos: "A aplicação feita incorretamente, em excesso e a não aplicação do tempo, da mente e dos objetos dos sentidos são a tripla propiciação da causa das doenças, tanto dos órgãos dos sentidos quanto da mente. O corpo e a mente dos seres são a sede das doenças bem como dos prazeres. O uso correto, então, é a causa dos prazeres".

\section{A doutrina dos três humores e dos cinco elementos}

A doutrina dos três humores ou tridosha vidya nos ensina que as funções corporais e mentais são controladas pelos três humores principais: Vata ou Ar, que controla todos os movimentos internos e externos no corpo; Pitta ou Fogo, que promove todos os processos de transformação, sejam digestivos, enzimáticos ou hormonais e Kapha ou Shleshman, elemento Água, responsável pela lubrificação, nutrição e estruturação do corpo e da mente. Cada um desses humores, engloba um segundo elemento complementar, que compõe suas ações fisiológicas. Assim, Vata é composto dos elementos Ar e Espaço, Pitta, combina os elementos Fogo e um pouco do elemento Água, que o estabiliza para que o elemento Fogo não seja consumido por si próprio e Kapha, composto pela Água e pelo elemento Terra que lhe 
dá contenção $(\mathrm{p} .5)^{8}$.

Vata, aquele que põe toda a existência em movimento, além de movimentar os outros dois humores, Pitta e Kapha, permite à mente adaptar-se e compreender, animando nosso aparelho sensorial. Por ser composto dos elementos Espaço (vacuidade e aridez) e $\operatorname{Ar}$ (movimento) Vata é seco, leve, frio, áspero, sutil e agitado. Forma indivíduos que, quando saudáveis, apresentam entusiasmo, flexibilidade, adaptabilidade, boa comunicação, criatividade e rapidez para aprender, pela mente viva e ativa que possuem. Porém quando em excesso, promove facilidade para esquecer, ansiedade, inconstância, insegurança, indecisão, agitação, medo, estimula ações desonestas, depressão, perversões de todo tipo, levando os indivíduos Vata à dependência química e à autodestruição. Pela velocidade da vida moderna, encontramos atualmente um grande número de indivíduos com desorganização de Vata, o princípio do movimento, com suas consequências mais comuns como o emagrecimento, debilidade, a insônia, a dificuldade de concentração, a constipação intestinal e as doenças degenerativas do sistema nervoso e do tecido osteoarticular.

Pitta, o humor que "digere" e que transforma, é responsável por todas as mudanças mentais, metabólicas e químicas que ocorrem no corpo. Ele "ilumina" também nosso Intelecto nos permitindo compreender e perceber com grande assertividade a realidade sem fantasias. Por ser composto de Fogo e Água, Pitta é levemente oleoso, agudo, quente, leve, de mau odor, móvel e líquido. Percepção, inteligência, inventividade, lógica, coragem e liderança são características de um Pitta equilibrado. Quando o elemento Fogo intensifica e se desajusta promove sensações de queimação e alterações na coloração da pele, da urina e das fezes que ficam de cor amarelo intenso. Também ocorre a irritabilidade, a ambição desmedida, a raiva, a crítica excessiva, a audácia, o orgulho, a dominação, a precipitação por excesso de confiança, a manipulação pelo poder, a rigidez, o ódio, o desejo de vingança, a vaidade excessiva, o desejo de destruição, as psicopatias e algumas ações criminais, com destruição do outro. Ainda frequentes, mas menos numerosos que os indivíduos Vata as alterações do elemento Fogo trazem doenças inflamatórias e febris, doenças hepáticas, sobretudo inflamatórias, doenças de pele, alterações hormonais, abscessos, problemas da visão e intolerâncias alimentares.

Kapha, o humor que mantém as coisas unidas (elemento Água) e que fornece o suporte para manifestação dos outros humores (elemento Terra), mantém nosso emocional e sentimentos como amor, compaixão, paciência e perdão. As características dos elementos que compõem Kapha lhe conferem uma condição fria, úmida, pesada, pegajosa, macia, sólida e lenta. Quando os elementos Água e Terra estão em equilíbrio e em proporções adequadas promovem estabilidade, calma, paz, compaixão, paciência, suavidade, receptividade, perdão, alegria, resistência, fé e amorosidade. Porém quando se desajustam e ultrapassam os outros elementos provocam náuseas, sensação de peso, palidez, sonolência, calafrios, apego, cobiça, materialismo, sentimentalismo, luxúria, necessidade desmedida de segurança, lentidão, acomodação, apatia, depressão, rudeza, letargia e tendência ao roubo, pela maior necessidade de segurança material. Os desequilíbrios dos elementos Água e Terra são os menos frequentes atualmente e quando ocorrem provocam as doenças respiratórias, sobretudo alérgicas, sinusites, os edemas não inflamatórios, principalmente linfáticos, as deficiências imunológicas e as doenças de acúmulo como o diabetes, a hiperuricemia e a hipercolesterolemia.

Descrito no capítulo XII do Caraka Samhita (p.81$2)^{6}$, encontramos a definição dos doshas, que embora estejam presentes em todos os tecidos corporais, ocupam preferencialmente determinadas regiões. Assim Vata se localiza principalmente no cólon, coxas, quadris, ossos, ouvidos e órgãos do tato. Pitta está no intestino delgado, estomago (área produtora de ácido), glândulas sudoríparas e sebáceas, no sangue e na visão. Kapha ocupa o peito, nariz, garganta, cabeça, pâncreas, estomago (área produtora de muco), linfa, tecido gorduroso, nariz (olfato) e língua (paladar). Quando a doença se manifesta nos locais preferenciais de cada humor (dosha), considera-se que o quadro patológico é inicial e de mais fácil tratamento e o retorno à integridade da saúde é rápido. Porém, quando as manifestações de sintomas dos doshas ocorrem em órgão fora do seu domínio, as doenças são mais graves e de mais difícil solução.

\section{O processo evolutivo da doença - A fisiopatologia segundo o Ayurveda}

Segundo o Ayurveda o processo de manifestação das doenças ocorre em seis estágios evolutivos que iniciam pelas manifestações dos humores nos seus locais preferenciais no sistema digestório, até sua localização com comprometimento de órgãos vitais. São eles: acúmulo (Sancaya), agravação (prakopa), hiperfluxo (prasara), deslocamento (sthana samçraya), manifestação (vyakti) e diferenciação (bheda) (p.119). ${ }^{9}$

No primeiro estágio ou de Acúmulo, os doshas ou humores se concentram inicialmente nos seus locais de origem no aparelho digestório. O Acúmulo ocorre em função de dietas, horários de alimentação e rotinas de vida inadequados, distúrbios psicológicos, falta de ajuste às mudanças de estação e exposição aos fatores de agravação de cada dosha. O Ayurveda defende que quando os humores permanecem no aparelho digestório e não se acumulam, o estado de saúde é mantido. Na fase de acúmulo, Vata aumenta no cólon, seu órgão preferencial, causando distensão, constipação, fadiga, secura nas fezes e alguma dificuldade para dormir, sintomas que aparecem preferencialmente no outono, estação seca e fria como Vata, 
composto de Ar e Espaço. Pitta acumulado no intestino delgado produz coloração amarela intensa nas fezes e urina, sensações difusas de queimação, hiperacidez, febres recorrentes, sabor amargo na boca e desejo de alimentos e bebidas frias, o que mais frequentemente ocorre no final de primavera e verão, estações quentes e úmidas como Pitta, composto de Fogo e Água. Kapha acumulado no estomago, leva à palidez, náuseas, digestão irregular ou lenta, sensação de peso no epigástrio, edemas frios e desejo por alimentos leves. Essas alterações são mais frequentes no inverno e início da primavera, períodos mais frios e úmidos como o Kapha, composto pelos elementos Água e Terra. Quando adequadamente tratados nessa fase, os sintomas de excesso de cada humor apresentam pronta involução e a cura é fácil e rápida. Muitas vezes, apenas corrigindo erros de rotina e alimentação e orientando-se mudanças de alguns comportamentos e condutas já se alcança remissão total dos sintomas, sem que o uso de medicamentos ou outros procedimentos sejam necessários.

No segundo estágio, o de Agravação, os doshas continuam a aumentar nos seus respectivos locais no aparelho digestório, promovendo um aumento na intensidade dos sintomas e alguns sintomas leves em outros locais. Assim, em Vata a constipação aumenta, a cabeça parece vazia, a distensão abdominal se generaliza, produzindo dores e espasmos e surgem ruídos audíveis nos intestinos. Pitta agravado traz maior sensação de acidez nas regurgitações pois o refluxo se instala, dor em queimação no abdômen, sede excessiva, perda de vigor e sono inquieto. Kapha agravado faz desaparecer o apetite, provoca indigestão e náuseas após refeições, aumenta a salivação, provoca intensa sonolência e a sensação de peso na cabeça e no peito passam a se apresentar com mais constância.

Na terceira fase o de Hiperfluxo, os doshas, tendo completado o máximo de acúmulo e agravação nos seus respectivos órgãos de origem, começam a se deslocar através do sangue e linfa para outros lugares do corpo, fora do aparelho digestório. Podem seguir em qualquer direção, em geral para pontos de menor resistência, determinados geneticamente ou por lesão anterior. Vata causa secura na pele, dor e rigidez nas articulações, que mais secas crepitam aos movimentos, dor lombar (lombociatalgias), espasmos, cefaleias, tosse seca, febre intermitente (alternando com calafrios), fadiga, constipação com evacuações difíceis e dolorosas e convulsões. Pitta leva a doenças inflamatórias de pele e mucosas, conjuntivite, gengivite, vertigens com calor na cabeça, cefaleias pulsantes, febre alta, vômitos biliares, bem como diarreias ácidas e que provocam escoriação no períneo. Kapha causa tosses constantes, asma, febres baixas com sudorese fria, edema frio nas articulações, gânglios aumentados e presença de muco nas fezes. Nessa fase o quadro de doença ainda tem bom prognóstico se tratado de imediato. Além da adequação de alimentação e rotinas, já se faz necessário complementação com outros tratamentos.

No quarto estágio, o de Deslocamento, os humores já deslocados do seu local de origem, provocam sintomas não só no aparelho digestório, mas se estabelecem em órgãos à distância podendo provocar centenas de diferentes sintomas. Em relação ao estágio anterior, aqui os sintomas são mais fixos e quando estabilizados, conferem prognósticos mais reservados, por que os quadros funcionais se tornaram gradativamente lesões anatômicas.

A Manifestação, no quinto estágio, os humores se manifestam por sintomas específicos e as doenças surgem com o que a medicina ocidental chama de entidades nosológicas definidas, com seus sinais e sintomas patognomônicos. No Ayurveda essas doenças poderiam ser tratadas muito antes, sem chegar a manifestar seus sintomas com tanta gravidade, pois os sintomas prodrômicos descritos anteriormente, sobretudo quando as manifestações ocorriam pelas alterações dos humores ainda no aparelho digestório, já seriam os sinais de alerta para início de tratamentos e prevenção de agravações.

No último estágio, o de Diversificação, os sintomas já instalados em órgãos específicos se agravam e os quadros clínicos se manifestam em toda sua complexidade, e com sintomas lesionais bem adiantados trazendo as consequências das complicações das várias doenças crônicas em órgãos vitais, em geral incuráveis e que determinam sofrimento, limitações e morte.

\section{Os sete tecidos funcionais (dhatus) - A fisiologia segundo o Ayurveda}

A definição de tecidos no Ayurveda tem um caráter muito mais funcional do que anatômico. São definidos sete tecidos (dhatus) com suas principais funções: plasma (rasa), responsável pela nutrição; sangue (rakta), vitalidade e distribuição de nutrientes; músculo (mamsa), sistema de locomoção; gordura (medas), processos de hidratação e lubrificação de tecidos; ossos (asthi), sistema de sustentação; medula, tanto óssea como vertebral e tecido conjuntivo (majja), preenchimento e controle; tecido germinativo (shukra), responsável pela procriação. Estão intimamente interligados e o comprometimento funcional de um, afeta um pouco o que o precede, mas principalmente o que o segue. Assim, como exemplo, a infertilidade, alteração funcional do tecido germinativo, pode ser causado por alterações no metabolismo do tecido que o precede, a medula (majja) que não fornece os nutrientes necessários para que as funções germinativas ocorram (p.21) ${ }^{10}$.

São definidos sintomas de alerta que apontam o mal funcionamento de cada tecido. Em resumo, para o tecido de nutrição (rasa), inquietude, palpitação, dor précordial, hipersensibilidade a ruídos, falta de vitalidade; para o sangue (rakta), aspereza, secura e fissuras na pele, perda de vigor físico e mental; para o tecido muscular (mamsa), emagrecimento, sobretudo nos quadris, pescoço 
e abdômen; para o tecido gorduroso (medas), crepitação nas articulações, emagrecimento excessivo com força muscular razoável, exaustão, fraqueza especificamente nos músculos dos olhos; no tecido ósseo (asthi), queda de cabelos, de unhas, amolecimento dos dentes e frouxidão nas articulações, com entorses por mínimos esforços; na medula (majjä), emagrecimento com fraqueza intensa generalizada, doenças Vata dos ossos, como crepitação articular dolorosa, artroses e osteopenia; no tecido reprodutivo (shukra), comportamento adinâmico, boca seca, palidez, lassidão, falta de resistência ao mínimo esforço, impotência e ausência de ejaculação nos contatos sexuais. Embora cada tecido seja governado por um humor diferente, nos casos de grandes descompensações, os tecidos podem ser invadidos por qualquer humor, com seus sintomas correspondentes. Com exceção do tecido sanguíneo, Rakta, controlado pelo elemento Fogo (Pitta), e do tecido ósseo, Asthi, controlado pelos elementos Ar e Espaço (Vata), todos os outros tecidos são controlados pelos elementos Água e Terra (Kapha), lembrando que setenta por cento da composição corporal é de água.

\section{Srotas - O sistema de circulação dos humores}

São descritos nos textos, inúmeros canais de circulação de materiais, densos como alimentos, fezes e urina ou sutis como emoções e energia vital. Pelo fluxo livre por esses canais são nutridos os vários tecidos corporais, além de outros componentes já descritos. Quando pérvios para a circulação dos seus conteúdos, se instala o estado de bem estar e saúde. Obstruídos para o livre trânsito dos seus nutrientes, alteram o normal funcionamento dos tecidos, por acúmulo ou por falta das substâncias que deveriam circular num padrão normal. Muitos desses canais se assemelham aos meridianos de energia da medicina chinesa, mas não são iguais numa comparação mais apurada. Os textos clássicos descrevem uma longa e minuciosa gama de sintomas correspondentes a bloqueios desses canais e tratamentos específicos para sua desobstrução. Assim três desses canais correspondem à comunicação do nosso corpo com o meio externo, do qual recebe energia: Pranavahashrota, ou canal de circulação de energia vital, relacionado basicamente ao nosso sistema respiratório e parte do sistema circulatório; annavahashrota, canal condutor de alimentos, corresponde ao sistema digestório; Ambhuvahashrotas, o canal regulador do metabolismo de água. Embora não tenha um correlato bem definido na medicina ocidental, engloba parte do aparelho digestório, sobretudo o pâncreas.

São listados também, sete canais de circulação de nutrientes para os sete tecidos corporais já descritos: rasavahashrotas nos quais circula a linfa, correspondendo ao sistema linfático; Raktavahashrotas carreadores de sangue e relacionados ao sistema circulatório; Mamsavahashrotas canais que alimentam os músculos e nossa capacidade de locomoção; medasvahashrotas mantenedor do tecido adiposo, lubrifica todos os órgãos sujeitos a atrito, como as pleuras e também as articulações; Asthivahashrotas são canais de circulação de nutrientes que dão suporte ao sistema esquelético, ao tecido ósseo e a todos os órgãos cujo arcabouço proteico é responsável por sustentação; Majjavahashrotas são os canais que nutrem a medula óssea, o tecido de preenchimento (correspondente ao tecido conjuntivo) e o sistema nervoso; Çukravahashrotas que mantém o sistema reprodutivo nos homens com os canais condutores de esperma e o Artavavahashrotas, que nas mulheres está relacionado às trompas que conduzem as células germinativas e ao útero nas menstruações.

São descritos três canais, conectados com o meio externo, mas responsáveis pela saída de materiais de exoneração do corpo: Svedavahashrotas que carregam o suor e o produto das glândulas sebáceas para a pele; Purishavahashrotas são canais densos de condução de fezes para fora do corpo, relativos ao íleo terminal e cólon; Mutravahashrotas são os canais que carregam e eliminam a urina, correspondendo ao sistema urinário.

As mulheres possuem dois sistemas exclusivos do sexo feminino: Artavavahaçrotas que conduz o sangue menstrual para fora do corpo mensalmente e o Stanyavahaçrotas que carregam o leite materno das glândulas mamárias aos bebês. Alguns autores não o consideram um canal isolado, mas parte do Artavavahaçrotas.

Manovahaçrotas é um dos sistemas de canais mais importantes por que alimenta a mente e transporta seus produtos, os pensamentos. No Ayurveda se considera a mente um órgão com funções independentes do sistema nervoso (majjavahaçrotas) tal qual o condutor e seu automóvel. Embora interligados, ambos têm funções complementares, mas exclusivas. Manovahaçrotas são canais que transportam os pensamentos e tudo que se relaciona a eles, inclusive os comandos direcionados a cada parte da fisiologia, sob controle total da mente (p.10). ${ }^{2}$

\section{Propensão às doenças}

O Ayurveda, como vimos, dá grande importância à compreensão dos mecanismos de instalação das doenças, por que sobretudo foca seus esforços na manutenção da saúde e na prevenção de doenças. Nossos sistemas corporais, quando em perfeito estado de funcionamento, transformam adequadamente todo alimento, água e ar introduzidos no corpo, além de todo conhecimento adquirido pela mente e pela consciência, em energia pura, responsável por uma saúde integral. Essa energia pura no Ayurveda é chamada de Ojas e é considerada a sustentadora da vida. Os textos não são claros se Ojas é uma substância física ou sutil, mas a localizam na região do coração, de onde se dissemina para todas as direções, mantendo a vitalidade de todas as funções, físicas e psíquicas. É mantida por alimentações adequadas em quantidade e qualidade, hábitos saudáveis de 
vida, como atividade física leve, atividades prazerosas da mente, ambientes naturais e agradáveis, boas e adequadas horas de sono e sentimentos como amor, felicidade e compaixão. A constituição individual, construída pelo predomínio de um ou outro dosha, porém, quando funciona de forma defectiva, determina todas as nossas tendências patológicas, sejam físicas ou mentais. Os desarranjos que se iniciam na parte do aparelho digestório específico de cada dosha (Vata no cólon, Pitta no intestino delgado e Kapha no estomago) se disseminam pelo resto do corpo, invadindo os órgãos vitais causando danos, sendo os responsáveis por todas as doenças que gradativamente se instalam tanto a nível físico como a nível psíquico. Muitos transtornos também podem iniciar diretamente por fatores psicológicos. Assim, medo (elemento Ar), raiva (elemento Fogo) e apego excessivo (elemento Água), determinam um início de desequilíbrio que pode se projetar no corpo físico, respectivamente em indivíduos Vata, Pitta ou Kapha. O medo reprimido (elemento Ar) desarranja Vata, a raiva (elemento Fogo) altera Pitta e a inveja, o apego e a desmedida busca por segurança (elemento Água e Terra), desarranjam Kapha, tornando o corpo e a mente suscetíveis às doenças (p.38) ${ }^{11}$. Além dos alimentos e das emoções, são também muito importantes nossos hábitos diários e nosso meio ambiente. É surpreendente pensar que o Ayuveda há milênios atrás já se preocupava com o meio ambiente, quando essa preocupação só passou a ser relevante para o ocidente há bem pouco tempo. Nossos hábitos diários, como horários de acordar, de refeições e de sono são também preocupações de primeira linha e a cronobiologia moderna tem confirmado a importância desses ciclos biológicos na integridade da fisiologia dos seres vivos. Os processos de transformações metabólicas que modernamente chamamos de sistema enzimático e hormonal, no sistema do Ayurveda é chamado de Agni (fogo). Embora controlado principalmente pelo elemento Fogo (Pitta), Agni também é estimulado e transportado pelo princípio do movimento, o elemento Ar (Vata) e deve ser controlado na sua intensidade pelos elementos Água e Terra (Kapha). Influenciado pelo sistema Tridosha (Vata, Pitta e Kapha), Agni controla todos os sistemas fisiológicos incluindo a produção de enzimas de toda natureza, o sistema hormonal, o sistema imunológico e também a "digestão" das ideias e das experiências vividas através da inteligência, compreensão e entendimento. Um bom Agni garante longevidade com vida plena e saudável e um Agni fraco ou excessivo afeta drasticamente todas as funções físicas e mentais. Quando Agni se altera, alimentos e emoções "mal digeridos" alteram o adequado aproveitamento, tanto dos nutrientes materiais dos alimentos, quanto das experiências vividas no dia a dia no campo psíquico, criando dessa forma toxinas físicas e mentais responsáveis por todos os transtornos do corpo e da mente. Esses produtos tóxicos são chamados no Ayurveda de Ama e são os grandes vilões na construção das doenças físicas e psíquicas, antagonizando os efeitos benéficos de Ojas, já descrito (p.41) ${ }^{11}$.

Outro importante fator a se considerar na gênese das doenças é a irregularidade no sistema de excreção corporal. Para que a saúde seja adequada, todo produto resultante de metabolismo, físico ou mental que não é mais útil, deve ser adequadamente eliminado. Esses produtos são chamados no Ayurveda de Malas (excretas). Os três principais Malas físicos são as fezes, a urina e o suor. A diferença entre Ama (produtos tóxicos produzidos pela digestão inadequada) e Malas (produtos finais de uma digestão adequada) é que esses últimos, antes de serem eliminados pelo corpo auxiliam na nutrição e tonificação dos órgãos que ocupam e só vão trazer algum problema para nossa fisiologia, quando se acumulam por falta de eliminação. As fezes, além de alguns nutrientes que nela permanecem, ainda fornecem apreciáveis quantidades de água ao cólon e mantém o tônus muscular do intestino, antes de serem eliminadas. O suor e a urina também são úteis na regulação hidroeletrolítica, na umidade da pele e no controle da temperatura do corpo. Suas eliminações determinam também o equilíbrio entre os três humores Vata, Pitta e Kapha. São considerados elementos de excreção secundários, as unhas, os pelos e cabelos, e na mulher, a menstruação. Através dos aspectos dos produtos eliminados, como cor, odor, consistência e regularidade, muitos diagnósticos podem ser feitos no Ayurveda pela observação dos excretas.

\section{Diagnóstico}

Se lembrarmos que exames laboratoriais não existiam, mesmo num passado recente, a observação detalhada de sintomas e sinais era de extrema importância para um diagnóstico preciso e um tratamento eficiente. As formas corporais falam muito a respeito da constituição de um indivíduo. A irregularidade e inconstância nas formas, como por exemplo a implantação das orelhas em alturas diferentes de cada lado fala a favor da constituição Vata; ângulos bem definidos e simetria quase perfeita, fala a favor de Pitta; as formas arredondadas predominam em indivíduos Kapha. A coloração de secreções e da pele também pode definir um diagnóstico. A coloração escura e sem brilho é própria de Vata, amarelo e vermelho definem Pitta e a palidez e a cor branca caracterizam Kapha. Temperatura e umidade também são parâmetros úteis como guias diagnósticos. Vata tem a pele fria e seca (elementos Espaço e Ar), Pitta (elementos Fogo e Água) tem a pele quente e úmida e Kapha (elementos Água e Terra) fria e úmida.

O comportamento também é resultado das forças dos elementos que movem a constituição. Indivíduos Vata, quando equilibrados, são ativos, adaptáveis, flexíveis e de rápida compreensão, entusiastas e bons em comunicação. Desequilibrados se tornam indecisos, hiperativos, ansiosos, loquazes, medrosos, depressivos, pervertidos e auto destrutivos. Indivíduos Pitta em equilíbrio 
são inteligentes, claros, perceptivos, independentes, corajosos, líderes e arrojados. Descompensados se tornam impulsivos, ambiciosos, agressivos, manipuladores, raivosos, orgulhosos, vingativos e destrutivos dos outros. Kapha determina, quando em equilíbrio, indivíduos calmos, pacíficos, alegres, estáveis, consistentes, leais, amorosos, compassivos, pacientes, devotados e com muita fé. Em estados de não compensação se mostram apegados, materialistas, sentimentais, inseguros, entorpecidos, apáticos, embotados, buscando conforto material excessivo e a luxúria como válvula de escape de suas apreensões.

A descrição pormenorizada dos sintomas também determina não só o elemento que se encontra em desequilíbrio, mas também seu estágio de descompensação, a localização, os tecidos e canais envolvidos no desequilíbrio além dos prognósticos de cura com os tratamentos adequados.

A observação dos elementos de exoneração como as unhas, pelos, cabelos, informações sobre a transpiração, as evacuações de fezes e urina e nas mulheres da menstruação e do aleitamento podem dar importantes informações diagnósticas.

O exame da língua é de fundamental importância. A forma, a espessura, a umidade, o odor, a presença, a cor e a distribuição da saburra, alinhamento da linha central, presença da marca dos dentes nas bordas da língua e a observação de movimentos involuntários são fortemente indicativos de desequilíbrios. A saburra escura aponta desequilíbrios de Vata, a amarela de Pitta e a esbranquiçada e pegajosa é característica de Kapha. A presença de saburra em diferentes áreas corresponde à representação dos vários órgãos do corpo nessas diferentes áreas da língua. $\mathrm{O}$ tremor involuntário da língua expõe um estado de ansiedade crônica, por desarranjo intenso de Vata (p.60-2). ${ }^{11}$

Porém, entre todos os exames, a exemplo do que ocorre também na medicina tradicional chinesa, o exame de pulso é o mais exato e mais reverenciado por todos os grandes médicos do Ayurveda. O exame de pulso necessita de extrema concentração e boa sensibilidade tátil, para se perceber em qual dos três dedos utilizados no exame (indicador, médio e anular) a batida do pulso é mais fortemente percebida. A forma como sentimos a pulsação também tem muito a nos dizer. Os textos clássicos, sobretudo o Sarngadhara Samhita (p.14) ${ }^{8}$ afirma que a sensação do pulso Vata (pela inconstância do elemento $\mathrm{Ar}$ e vacuidade do elemento Espaço) é percebida como um pulso fraco semelhante a passagem de uma serpente ou de um verme no dedo indicador do examinador; Pitta, intenso pelo elemento fogo, produz um pulso agudo no dedo médio, como o salto de um sapo e a suavidade do elemento água e a estabilidade do elemento Terra produz um pulso cheio, mas suave como o deslizar de um cisne num lago, no dedo anelar. As sensações porém podem se apresentar fora do contexto de normalidade e uma grande variedade de padrões de pulso são descritos, determinando de forma precisa um grande número de doenças que devem ser tratadas. Só para se ter uma ideia da riqueza do exame de pulso, podemos identificar duzentas e dez informações ao examinar o pulso de um paciente. Sentimos o pulso em ambos os lados, percebendo a pulsação em cinco regiões de cada um dos três dedos utilizados no exame e em sete níveis de profundidade diferentes ${ }^{1213}$.

\section{Tratamentos}

O ponto principal dos tratamentos em Ayurveda é restabelecer as funções adequadas dos doshas Vata, Pitta e Kapha. Para isso, a primeira coisa que se busca é entender os mecanismos físicos e mentais que levaram os indivíduos a alterarem essas funções e inicialmente corrigir a rotina diária (dinacharya) para impedir que novos produtos tóxicos (Ama) sejam formados. Na grande maioria dos casos isso já é suficiente para a saúde ser restabelecida, sobretudo em indivíduos jovens e com quadros clínicos funcionais. $\mathrm{Na}$ rotina diária são incluídos novos hábitos, baseados em horários previamente determinados e que, segundo o Ayurveda, são os momentos em que cada órgão dispõe da sua maior concentração de energia para desempenho das suas funções. Só como exemplo, podemos citar a biodisponibilidade do aparelho digestório por volta do meio dia, pico da energia de Pitta, elemento Fogo, coincidindo com o ápice da posição do Sol no céu e que, em qualquer lugar do planeta, corresponde à hora do almoço. Assim cada conselho da rotina diária é baseado no predomínio de cada um dos cinco elementos nas vinte e quatro horas do dia. A identificação de desequilíbrios emocionais é sempre valorizado pois emoções reprimidas são forte formadoras de toxinas $(A m a)$. Uma das melhores maneiras de lidar com as emoções é aprender a observá-las quando elas se expressarem, focando a atenção não na emoção em si, mas nos mecanismos de desequilíbrio que elas desencadeiam. Com o hábito de observá-las, tornamos as emoções passíveis de serem superadas, sem necessariamente se manifestarem. Cada dosha tem emoções predominantes em função dos elementos que o compõem. Assim, a ansiedade e o medo são mais comuns em indivíduos Vata; é comum para um Pitta sentir raiva e indignação; pacientes Kapha, frequentemente expressam sua insegurança e sofrimento por apego e por perdas afetivas e materiais. Segundo o Ayurveda, o medo afeta os rins, a raiva desorganiza o fígado, o apego, agride o coração e avidez por valores materiais altera o baço. Quando apenas as rotinas de horários de alimentação, sono e atividade física não são suficientes para o restabelecimento seguro da saúde, procedimentos de neutralização de toxinas já profundamente instaladas em órgãos vitais são necessários.

Para esses casos, o Ayurveda indica o Panchakarma (cinco ações) que procura deslocar, remover e eliminar toxinas acumuladas por longos períodos de negligência aos cuidados com a saúde ${ }^{14}$. Depois de uma preparação 
prévia de uma a três semanas (purvakarma) com chás de ervas promotoras de desintoxicação, dieta hipotóxica a base de vegetais cozidos, ingestão de óleos (oleação interna), massagens com óleos medicinais (oleação externa) e banhos de vapor, inicia-se o Panchakarma propriamente dito. Nesse tratamento são descritos cinco terapias para remoção do excesso dos doshas Vata, Pitta e Kapha: Vamana, ou vômito terapêutico, em que é dado ao paciente três ou quatro copos de chá de cálamo aromático associado a outras ervas medicinais ou alcaçuz e após alguns minutos se provoca o vômito. Terapeuticamente está indicado para o excesso de Kapha e seus sintomas como a congestão brônquica, dos seios da face, para a tosse crônica, para a asma e também para o diabetes (acúmulo de açúcar no sangue) na hipercolesterolemia, em obstruções linfáticas, edemas, digestão lenta e amidalites de repetição. Outros acúmulos de elementos Água e Terra, como as emoções de Kapha de apego e insegurança também encontram indicação de vamanas. Outro procedimento incluído no Panchakarma é o uso de ervas purgativas, Virechana, para retirada do excesso de Pitta e suas toxinas do fígado, vesícula biliar e intestinos que provocam lesões inflamatórias da pele, rashes cutâneos, acne, dermatite, febre crônica, abscessos de glândulas sudoríparas, ascite, hemorroidas, gota e icterícia, além de outras doenças dos elementos Fogo e Água (secundariamente). Um terceiro tratamento do Panchakarma são os enemas de ervas (Niruha) ou de óleos medicinais (anuvasana) introduzidos no reto, visando o tratamento do cólon em descompensações dos elementos Espaço e Ar dos indivíduos Vata. São indicados para a constipação crônica, ciática, doenças reumáticas, artroses, atrofia muscular, desordens do sistema nervoso, cefaleias não pulsáteis (a pulsação é uma indicação de tratamentos anti Pitta), cálculos renais e distúrbios sexuais. Como Vata é responsável por uma gama apreciável de patologias, os bastis são usados em tratamentos de inúmeras doenças. Nasya é outro componente do Panchakarma e consiste na administração de medicações por via nasal. Está indicado no acúmulo de doshas na garganta, nariz, seios da face e cabeça por que o nariz é a abertura do corpo mais próxima para a saída de toxinas. As preparações medicinais podem ser administradas como pós para aspiração (virechana nasal), óleos de ação sedativa e nutritiva para Vata, decocções de ervas com as mais variadas indicações para sistema nervoso e massagens nasais para alívio de cefaleias agudas ou crônicas, rinites, rouquidão, sinusites, linfadenites cervicais, vertigens, epilepsia (estados intercríticos), Parkinsonismo e alterações psíquicas relativas a Vata, Pitta e Kapha, já que o nariz, para o Ayurveda é considerado a porta de entrada para o cérebro e para a consciência ${ }^{15}$. Como o nervo olfatório é relativamente superficial e liga a mucosa nasal ao sistema nervoso central, as massagens nasais são consideradas sedantes potentes de emoções bloqueadas. Nos períodos de clima seco, a massagem interna das narinas com óleo de gergelim, traz imenso conforto e previne sangramentos. A quinta e última ação terapêutica do Panchakarma, as retiradas de sangue de áreas de congestão sanguínea (rakta moksha) tem indicações sobretudo nas doenças Pitta, já que os elementos Fogo e Água controlam o sangue e o sistema circulatório. Assim, as doenças crônicas de pele, sobretudo as inflamatórias mas também os aumentos de baço e fígado, as varizes, as hemorroidas, as doenças inflamatórias articulares e a Gota encontram alívio com sangrias em áreas específicas. Convém ressaltar que são retiradas pequenas quantidades de sangue e em nada se compara às técnicas de sangria que se praticava na Idade Média que espoliavam os indivíduos que se submetiam a elas e que frequentemente os levava à morte.

Após aplicações de Panchakarma, o Ayurveda aconselha as medidas pós desintoxicação (uttara karma) com estimulantes de enzimas digestivas como as ervas quentes e pungentes como o gengibre e um pouco de sal, o limão, a pimenta preta, os chás de erva doce e raiz de bardana e sucos de lima da Pérsia ou de romã além de uma dieta leve por mais alguns dias, o que complementa a desintoxicação ${ }^{16}$. Além do Panchakarma, outras formas de tratamento também são indicados como o aconselhamento dietético específico para cada dosha, Vata, Pitta e Kapha, através de extensas listas de alimentos específicos encontradas nos vários textos modernos de Ayurveda (p.82-4) ${ }^{11}$.

Lembrando que o Ayurveda teve também a escola cirúrgica de Sushruta, vários procedimentos cirúrgicos foram disponibilizados, tanto na reparação de tecidos lesados por acidentes ou batalhas, como também na excisão de tumores, no esvaziamento de ascite e na drenagem de abscessos que já eram realizados pelos cirurgiões do Ayurveda, segundo relatos de textos do século IV a.C. (p.iii) . Além de vários instrumentos cirúrgicos, muitas técnicas de cirurgia do Ayurveda antigo são utilizadas até hoje com mínimas modificações. Surpreendente para a época em que foi descrito, o chamado "retalho indiano" é utilizado na cirurgia plástica dos dias de hoje, mais de dois mil anos depois que foi descrito. Essa técnica consiste em um retalho pediculado rodado da região frontal, para reconstrução de perda do nariz. A reconstrução nasal era uma cirurgia comumente praticada numa época em que as batalhas de espada eram frequentes e também por que a pena para criminosos ou povos conquistados era a mutilação de alguma parte do corpo que os estigmatizasse, como a amputação do nariz, do lóbulo da orelha e até dos genitais. No ocidente, as técnicas cirúrgicas tiveram um grande período de estagnação, sobretudo por influência da igreja católica e até mesmo de religiões anteriores que proibiam a dissecção de cadáveres, considerada uma profanação. Na Europa isso só mudou após a liberação das dissecções pelo Papa Sixto V, em meados do século XVI e o retalho indiano só passou a ser descrito em livros de medicina ocidental, no "Magazine of Gentleman" publicado no século XVIII, dois séculos mais tarde, quando os procedimentos cirúrgicos no ocidente, passaram a ser 
mais comuns ${ }^{17}$.

Ainda como tratamento, lembramos a extensa farmacopeia indiana, com mais de dez mil plantas estudadas, algumas inclusive utilizadas no ocidente como fitoterápicos modernos $^{18,19}$. É importante citar também o estímulo dos vários pontos de energia e seus meridianos, assemelhados à medicina chinesa, que oferecem um recurso a mais de tratamento, seja pela aplicações de agulhas (acupuntura) ${ }^{20}$, como também pelo uso de óleos medicinais ou acupressão em massagens (marmaterapia) (p.173-90) .

Mesmo derivadas da mesma origem, o Ayurveda e o Yoga caminharam na antiguidade por caminhos separados, embora citados mutuamente em seus textos mais antigos. Só recentemente encontramos tratamentos em livros de Ayurveda que incluem práticas de posturas físicas, exercícios de respiração e meditação e relatos de procedimentos de

\section{REFERÊNCIAS}

1. Wujastyk D. The roots of Ayurveda. New Delhi: Penguin Books India; 1998.

2. Frawley D. Ayurvedic healing - a comprehensive guide. Delhi: Motilal Banarsidasss Publishers; 1989.

3. Bhishagratna KK, trad. The Susruta Samhita. Varanasi: Chowkhamba Sanskrit Series Office; 1996.

4. Ninivaggi FJ. Ayurveda: a comprehensive guide to traditional indian medicine for the west. Praeger: Greenwood Press; 2008.

5. Zysk KG. Medicine in the veda - religious healing in the veda. Delhi: Motilal Banarsidass Publishers; 1996

6. Sharma PV, trad. Caraka Samhita. Varanasi: Chaukhambha Orientalia; 1992.

7. Devesa ACRS. De Avyakta a Sphota. O percurso analógico da composição nominal na construção de sentido do texto médico Caraka Samhita [dissertação]. São Paulo: Universidade de São Paulo; 2000.

8. Murthy KRS, trad. Vaghbhata Astañga Hrdayam. Varanasi: Krishnadas Academy; 1991.

9. Carneiro DM. Ayurveda, saúde e longevidade na tradição milenar da Índia. São Paulo: Pensamento-Cultrix; 2008.

10. Murty KRS, trad. Sarngadhar-Samhita (a treatise on Ayurveda). Varanasi: Chaukhambha Orientalia; 1995.

11. Lad V. Ayurveda, the science of self-healing. A practical guide.
Ayurveda incluídos em conselhos para praticantes de Yoga, como forma de facilitar o caminho de desenvolvimento espiritual.

Temos certeza que esses conhecimentos milenares do Ayurveda, testados por várias gerações por aproximadamente cinco mil anos de história, teriam muito a contribuir com a medicina ocidental, desde que fossem vistos não como uma forma de conhecimento excêntrico, mas como uma arte na observação dos fenômenos físicos e psíquicos, com sua descrição detalhada de sinais e sintomas, tanto dos pródromos como dos sintomas mais avançados de uma doença. Também merecem estudos a extensa gama de recursos terapêuticos direcionados não apenas para cada estágio de desenvolvimento da doença, mas sobretudo pelo seu principal intuito, o de preservar a saúde e prevenir as doenças $^{21}$.
Wilmot: Lotus Press; 1985.

12. Upadhyay GP. The science of pulse examination in ayurveda. Delhi: Sri Satguru Publications; 1997.

13. Upadhyaya S. Nadi Vijñana - ancient pulse science. Varanasi: Chaukhamba Sanskrit Pratishthan; 1986.

14. Dash B, Kashyap L. Five specialised therapies of ayurveda (Pañca Karma). New Delhi: Concept Publishing Company; 1992.

15. Lele A, et al. Pancha-Karma and ayurvedic massage. Pune: International Academy of Ayurved; 1999.

16. Singh RH. Panca karma therapy. Varanasi: Chowkhamba Sanskrit Studies; 1992.

17. Lyons AS, Petrucelli RJ. Medicine - an illustrated history. New York: Harry Abrams; 1987.

18. Savnur HV. Ayurvedic materia medica with principles of pharmacology \& therapeutics. Delhi: Sri Sat guru Publications; 1988.

19. Dash B. Materia medica of ayurveda. Delhi: B. Jain Publishers; 1991.

20. Ros F. The lost secrets of ayurvedic acupuncture. Delhi: Motilal Banarsidass Publishers; 1997.

21. Murthy KRS, trad. Madhavanidanam of Madhavakara. Varanasi: Chaukhambha Orientalia; 1995. 